\title{
Interactive comment on "Changing patterns of extreme water levels in urbanizing plain river network region of Taihu Basin, China: characteristics and causes" by Y. Wang et al.
}

Anonymous Referee \#3

Received and published: 23 June 2016

The paper attempts to investigate the influence of climate change and human activity on changes of water levels in the plain river network region of Taihu Basin, China. Daily water level data from 8 monitoring stations and for the period 1962-2012 have been used in the analysis. Two time series representing annual maximum water levels and annual minimum water levels have been derived from the daily data for the 8 stations. One single regionalisation series for each of the two variables has then been calculated by averaging the time series from the 8 monitoring stations using the Thiessen polygons method. The resulting two regionalisation series have been analysed using basic statistical methods used in testing the significance of trend changes in a time series. I believe that averaging of the 8 time series in one single regional

Printer-friendly version

Discussion paper 
series represents a major flaw in the methodology of the paper. Some of the significant variations in each of the 8 time series could be smoothed out by this averaging and hence false results are obtained from the analysis. Therefore I suggest that the authors redo the analysis on each of the 8 time series separately and use the results of this analysis in answering the main research questions of the paper similar to the approach used by Murphey et al. (2013).

Murphy, C., Harrigan, S., Hall, J., and Wilby, R.L. (2013). Climate-driven trends in mean and high flows from a network of reference stations in Ireland. Hydrological Sciences Journal - Journal des Sciences Hydrologiques, 58 (4) 2013755. http://dx.doi.org/10.1080/02626667.2013.782407.

Some specific comments:

Mann-Kendall statistic $Z$ and two statistics UF and UB used in Figure 4 need to be described in Section 3.1.1.

In section 4.2 the authors need to justify why is the activity period (between 1989-2000) divided into two shorter periods.

More international references must be cited in the paper.

Interactive comment on Hydrol. Earth Syst. Sci. Discuss., doi:10.5194/hess-2016-184, 2016. 